\title{
EXPLORING A MENTAL SCALING EFFECT ON ONLINE CONSUMER RATINGS: IDENTIFICATION OF SHOPPING BEHAVIORS AND INFORMATION PROCESSING RULES
}

\author{
Jung Lee \\ Hankuk University of Foreign Studies \\ 81, Oedae-ro, Cheoin, Yongin, Gyeonggi, 17035, Korea \\ jung.lee@hufs.ac.kr \\ L. G. Pee \\ Nanyang Technological University \\ 31 Nanyang Link, \#05-06, Singapore 637718 \\ peelg@ntu.edu.sg
}

\begin{abstract}
This study examines how the same online consumer ratings can be perceived differently by consumers in different purchasing circumstances and demonstrates that the effects of ratings proportionally vary with scale and assessment types. By applying Weber's law, which explains the shifting perception of individuals on stimuli based on mental scaling mechanism, we hypothesize that the marginal effect of rating (i.e. when there is one product to value) and rating difference (i.e., when there are two products to compare) decrease as rating and rating difference increase. To validate this hypothesis, we conducted an experimental survey on 226 online shopping mall users. The results show the marginally decreasing effect of rating and rating difference on consumer purchase intention, thus supporting the different mental scaling systems in different situations. This study contributes to the literature by providing rationale for consideration of the scale and context of the rating when discussing the rating effect.
\end{abstract}

Keywords: Online Consumer Rating, Weber's Law, Marginally Decreasing Rating Effect, Mental Scaling Effect, Consumer Purchase Intention

\section{INTRODUCTION}

Online consumer rating has become one of the most influential product information sources for online shopping mall users because of its 
convenience in quantification and effectiveness in processing ${ }^{1}$. For example, average online ratings summarize how the majority of consumers evaluate a product, and the presented numerical value, such as 3.5 out of 5 , helps consumers easily value and compare multiple products on a website ${ }^{2}$. Online consumer rating is one of the basic product attributes that consumers verify before making purchase decisions. Consumers often narrow down the pool of products and select products based on ratings ${ }^{3,4}$.

Numerous studies have focused on online consumer rating because of its importance in the consumer decision-making process ${ }^{5,6}$. Researchers have verified basic reasoning, such as high ratings generally resulting in sales increase ${ }^{7}$, whereas others extended the scope of their study to other conditional factors, such as the spread of ratings ${ }^{8}$ and product types ${ }^{9}$, which moderate the perception of ratings. The asymmetric effects between positive and negative reviews have also been observed ${ }^{10}$.

However, despite these efforts, some studies failed to consider consumer-side situational factors in decision making, such as the purpose of online rating processing behavior. The contextual contingency of consumer in rating perception is important, because the same rating can be perceived and processed differently as consumers process rating information for different purposes and contexts ${ }^{11,12}$. For example, some consumers use consumer ratings to scan a large number of products easily and to narrow down the choices quickly from a large pool to a small basket ${ }^{13}$. Others use ratings to define the minimum quality level ${ }^{14}$ or to make a final decision between two attractive competing products ${ }^{15}$. If the purpose of rating information processing is different, the effects would naturally differ ${ }^{16}$. However, prior online rating studies did not consider the processing behaviour of consumers, but simply assumed that the same ratings would be processed similarly and will have a similar effect regardless of the consumers' purpose for using that information ${ }^{17}$.

Therefore, this study examines how consumers perceive specific ratings differently based on their processing purposes and behaviors. We categorize the rating information processing behaviors of consumers into two types: valuing and comparing. We also investigate how and why the effects of the same ratings would differ depending on the purposes of the behavior. This dichotomy of consumer behavior is drawn from the existing literature on the behavior of online shopping mall users ${ }^{18,19}$. It describes the step-by-step process of how online consumers continue their shopping until they find the product they want or until they stop purchasing.

We also introduce Weber's law as a theoretical lens by which to explain consumer perception regarding two different behaviors. This law explains the mental scaling effect of human beings when they are exposed to 
a certain stimulus ${ }^{20}$. Online consumer rating is one of the most important stimuli that consumers perceive and process when making purchase decisions. Consumers then apply the theory to provide rationale when analyzing the rating effect.

This study is organized as follows. First, we review the literature on online consumer rating and Weber's law. We then categorize consumer decision-making behaviors into two types and develop hypotheses about the rating effects for each type of behavior. Subsequently, we describe how the survey is designed and the data are collected. Lastly, with the data obtained from 226 online shopping mall users, we detail how the results support the hypotheses. In-depth discussions on the contributions and implications of the study are presented at the end.

\section{LITERATURE REVIEW}

\subsection{ONLINE SHOPPING PROCESS AND CONSUMER BEHAVIORS}

A group of studies on online shopping behaviors have focused on the factors related to consumer purchase activities such as risk, price, $\operatorname{trust}^{21}$, and satisfaction ${ }^{22}$. These studies broadly investigate consumer behaviors pre- and post-purchase by scanning contextual factors in the use of shopping mall, such as channel preference and gratification ${ }^{23,24,25}$.

Another group of studies focuses on the process of the consumer behaviors, such as searching and browsing, and examines how these different behaviors are strategically combined for a single shopping event ${ }^{26}$. Detlor et al. ${ }^{27}$ compared searching and browsing behaviors to understand consumers' information-seeking behaviour during the pre-purchase stage, whereas Senecal et al. ${ }^{28}$ presented a more unifying view by integrating an alternative searching process into the evaluation process.

More recently, another group of studies emerged which highlights the continuance and integration of the processes. For example, Teo and Yeong ${ }^{19}$ confirms the existence of two-step behaviors between the need for recognition and purchase, namely, information search and alternative evaluation. These categories imply the possibility of two different behaviors and purposes. Darley et al. ${ }^{29}$ illustrate a more integrative decision-making process that highlights the iteration between information search and alternative evaluation until people make a final purchase decision. To facilitate the continuance of the consumer journey, Edelman ${ }^{18}$ describes a more process-based consumer decision process that focuses more on the importance of web design. 


\subsection{Effect of Online Consumer Rating}

Numerous studies have scrutinized the effect of online consumer ratings ${ }^{13,30}$ because they have a critical influence on consumer decision making $^{31}$, and their effects are practically convenient to quantify, analyze, and interpret ${ }^{2}$. Ratings demonstrate the views of the majority of consumers on a product in a parsimonious format, such as average ratings between 3.5/5.0 and 4.8/5.0. When information is delivered in such a single-number format, it is more convenient for consumers to sort, compare, and screen ${ }^{32}$. As one of the most widely used statistics that illustrate the central tendency of the majority ${ }^{33}$, average online consumer rating has been the subject studied extensively in literature ${ }^{9}$.

Studies on online consumer ratings also developed their methodological aspects ${ }^{34}$. In the early research of ratings, a simple assumption indicated that high ratings would undoubtedly lead to high sales $^{35}$. However, researchers began to investigate further for more comprehensive and sophisticated relationships between ratings and other performance measures ${ }^{36}$. For example, Clemons et al. found not only the average but also the dispersion of ratings determines the sales ${ }^{3}$. Adams et al. also found that sales do not gradually increase as ratings increase and that they have critical points that abruptly change the sales ratings ${ }^{37}$. Moreover, the effect of ratings differs across product types ${ }^{17,30}$, and negative and positive ratings are not in opposing positions but have asymmetric effects ${ }^{38}$.

These studies on ratings reflect the comprehensiveness of the methodological aspects of the online rating analysis process ${ }^{39}$ but not in the circumstantial aspect of consumer behaviour and/or perceptions. These studies were conducted under an assumption that the same rating will display a similar effect regardless of the situation in which consumers make purchases $^{40}$. The present study, therefore, focuses on the consumer side of the rating perception - how the ratings are perceived differently by consumers - to enhance the understanding of online consumer rating effects $^{41}$.

\subsection{The Weber's Law: A Mental Scaling Mechanism on Ratings}

Weber's law explains the shifting perception of individuals on stimuli based on their mental scaling mechanism. For a long time, this concept has been widely applied in various disciplines from psychology to physiology ${ }^{42}$. Weber's law suggests that equally perceptible increments in a response correspond to proportional increments, instead of a numerical increment. The threshold of discrimination between two stimuli increases linearly with stimulus intensity ${ }^{20}$. Thus, the response of an individual to a change in 
stimulus will be inversely related to the absolute magnitude of the original stimulus $^{43}$.

Weber's law emphasizes that the perceived discrimination depends on the ratio that distinguishes the two sets of any stimuli and not on the difference between them ${ }^{20}$. For example, when a person is only sufficiently sensitive to distinguish a $105 \mathrm{~g}$ apple from that weighing $100 \mathrm{~g}$, he can only distinguish apples weighing $210 \mathrm{~g}$ from those weighing $200 \mathrm{~g}$ when the apples' masses are doubled and the differential threshold is also doubled to $10 \mathrm{~g}$. He would not be able to distinguish two apples weighing $205 \mathrm{~g}$ and $200 \mathrm{~g}^{44}$.

This concept has been applied frequently in business studies because of its effectiveness in explaining the seemingly unreasonable behavior of consumers regarding purchases ${ }^{45}$. For example, this law can explain why consumers would perceive a larger gap between $\$ 1$ and $\$ 2$ than that between $\$ 11$ and $\$ 12$ during shopping ${ }^{46}$. In addition, the law provides the explanation for why consumers do not seriously consider price variances and search hard for alternatives regardless of the option availability ${ }^{43}$. Furthermore, how consumers perceive various product packaging sizes ${ }^{47}$, brand switching ${ }^{48}$, and risk-level changes ${ }^{49}$ have been explained by applications of Weber's law.

In judging the differences between the intensities of two stimuli, it should be noted that Weber's law holds only over a limited range of stimulus intensity. Fechner later added that subjective sensation must be measured indirectly using differential increments, thus Weber-Fechner law was derived $^{46}$. Weber-Fechner law is discussed in tandem with Gossen's first law of diminishing marginal utility because of their similar curve shapes in the graph ${ }^{50}$. However, the two perspectives are different in that Gossen's first law stems from physics, indicating calculation as actual utility, while Weber's law describes mental scaling from the physiological perspective.

\section{THEORETICAL DEVELOPMENT}

\subsection{Purchase Decision-Making Process of Consumers: Iteration of Valuing and Comparing}

With the increasing number of products available in online shopping malls, consumers are provided with countless choices but subsequently face a highly complex and difficult product selection process 51 . When purchasing a TV set, a consumer may have to peruse thousands of TV sets on Amazon.com to find the best one. Even if this consumer narrowed down the products based on several criteria, such as brand and price, the filtered list would still be comprise more than twenty products, which the consumer 
would have to examine and compare thoroughly ${ }^{19}$. This consumer's decision-making process would end when the product that suits this consumer's desire and expectation is found or when the consumer aborts the search because of failure to find a suitable product ${ }^{29}$.

Drawing from the literature ${ }^{29}$, we propose that such complex and timeconsuming shopping processes involve two types of product assessment activities: valuing and comparing (see Table 1). When a consumer begins shopping online, he first narrows down his choices from a pool of products using various measures, such as brand, price, and rating ${ }^{18}$. He then investigates each product in detail to examine whether it fits his personal desire and expectation ${ }^{52}$. The first screening process involves productcomparing activities, whereas the second examination process involves product-valuing activities. If the consumer considers the examined and valued product as not suitable enough to be purchased, the consumer starts screening again and conducts further comparisons in search of the best product $^{29}$.

When valuing, a consumer estimates the value of a product using information from the Internet, which includes product specification, product image, and consumer rating ${ }^{51,53}$. This evaluation is conducted from an absolute perspective rather than from a relative perspective. The decision criteria used for evaluation may include, for example, whether the product meets the consumer's desire and expectation. Even the bestselling product that is better than other competing products may still not meet a particular consumer's desire and expectation ${ }^{3}$. Thus, even with high consumer satisfaction ratings, a product may still not fit a consumer's personal preference and/or expectation, because people have different tastes ${ }^{17}$. Each consumer has his own absolute level of product specification ${ }^{54}$. Thus, consumers evaluate products by considering their own standards and perspectives instead of adopting a relative perspective.

In contrast, when comparing, people estimate the value of multiple products from a relative perspective ${ }^{55}$. In this stage, consumers examine products to find the one that is better than the others instead of checking whether the quality of a specific product satisfies their minimum requirements. Given that product comparisons are made from a relative perspective, parameters such as size, rating, or class are often used ${ }^{2}$. These numeric parameters enable a consumer to compare products easily and judge which is better than others ${ }^{17}$. However, a consumer does not always purchase a product that has been judged as better than others because of the relativity of judgment. Instead, products are narrowed down by consumer choices and are eliminated if consumers are not interested ${ }^{56}$. 
Table 1. Online consumers' product assessment activities

\begin{tabular}{|c|c|c|c|c|c|}
\hline $\begin{array}{c}\text { Assessment } \\
\text { Type }\end{array}$ & $\begin{array}{l}\text { Assessing } \\
\text { Question }\end{array}$ & $\begin{array}{c}\text { Assessment } \\
\text { Process }\end{array}$ & Assessment View & $\begin{array}{l}\text { Consumer } \\
\text { Behavior }\end{array}$ & Reference \\
\hline Valuing & $\begin{array}{l}\text { "Is this } \\
\text { product } \\
\text { good } \\
\text { enough to } \\
\text { purchase? }\end{array}$ & $\begin{array}{l}\text { Judging whether } \\
\text { a specific } \\
\text { product meets } \\
\text { the consumer's } \\
\text { individual } \\
\text { desire, needs, } \\
\text { and expectation }\end{array}$ & $\begin{array}{l}\text { Absolute } \\
\text { perspective: A } \\
\text { product that is better } \\
\text { than others does not } \\
\text { guarantee consumer } \\
\text { satisfaction, when } \\
\text { consumer } \\
\text { expectation is high } \\
\text { and/or desire is } \\
\text { different. }\end{array}$ & \multirow{2}{*}{$\begin{array}{l}\text { A consumer } \\
\text { repeats } \\
\text { valuing and } \\
\text { comparing } \\
\text { until he } \\
\text { makes a final } \\
\text { decision. }\end{array}$} & \multirow[t]{2}{*}{$\begin{array}{c}18,19,29,51 \\
53,55\end{array}$} \\
\hline Comparing & $\begin{array}{l}\text { "Which } \\
\text { product is } \\
\text { better than } \\
\text { others?" }\end{array}$ & $\begin{array}{l}\text { Narrowing down } \\
\text { product } \\
\text { selections from } \\
\text { many to a few }\end{array}$ & $\begin{array}{l}\text { Relative perspective: } \\
\text { As long as a product } \\
\text { is better than others, } \\
\text { a consumer keeps the } \\
\text { better product in the } \\
\text { list and drops the } \\
\text { others. }\end{array}$ & & \\
\hline
\end{tabular}

\subsection{When Consumers Refer to Rating for Product Valuing}

When a consumer refers to online consumer ratings to estimate the overall value of a product, he usually checks the average rating of the product, which is displayed next to the product in a convenient format, such as stars and bold letters. The average rating of a product shows a central tendency of consumer ratings ${ }^{33}$ and helps consumers save time and effort when reading through all the reviews given to the products. Consumers perceive the average rating as a single number that shows the "general" and "overall" impression that the majority of consumers have of the product ${ }^{3}$.

When a single-numbered average rating, such as 4.2 , is perceived by a consumer, its magnitude is mathematically computed as a margin between a null rating and the given rating (i.e., $4.2=|4.2-0|$ ) following the rules of the decimal system we are familiar with. To support the idea of this margin with a theoretical framework, this study introduces the concept of "reference point," which sets the datum through which the consumer initiates his mental scaling ${ }^{57}$. This study defines the reference point as the datum at which the mental scaling on a given rating begins ${ }^{58}$. For example, when a consumer refers to a rating of 4.3 to value a product, the magnitude of the rating is perceived as 4.3 , based on the dominant decimal system that our society has been using for centuries. This calculation mechanism is 
grounded on the decimal system that dominates our mental scaling effects (see Table 2).

According to Weber's law, the perceived difference (discrimination) is proportional to the ratio that distinguishes two set sizes, not to the actual difference between them ${ }^{20}$. Hence, the marginal impact of the difference decreases as the difference itself increases ${ }^{59}$. As the difference equals the magnitude in the case of the product rating (e.g., the difference between 4.3 and 0 equals 4.3), the law is interpreted as follows: the perceived magnitude of the rating is proportional to the ratio that distinguishes the two sets of ratings (4.3 and 0 ). For example, the perceived difference between ratings of 1 and 2 equals the difference between ratings of 2 and 4, not between ratings 2 and 3. As Weber's law states, the marginal effect of a rating decreases as such rating increases ${ }^{20}$.

Such a nonlinear impact of rating is observed in various studies, especially when valuing a product. For example, Duan et al. ${ }^{60}$ found no significant relationship between the sales and rating of popular movies, which implies that the marginal increase of a rating may not have a significant impact as that in the case of Weber's law. Other studies ${ }^{13}$ also show the nonlinear effect of rating and discuss the moderating factors of the volume of review, consumer characteristic, and product type ${ }^{54}$. From this notion, we formulate the following hypothesis.

H1: When online consumer ratings are referred to in estimating the value of a product, the marginal impact of a rating on purchase intention decreases as rating increases.

\subsection{When Consumers Refer to Rating for Product Comparisons}

When consumers refer to rating to compare products, they observe two sets of ratings and compute the difference by subtracting a smaller number from a larger number. For example, if two products with the ratings of 3.9 and 4.3 are compared, the margin computed by the consumer is the difference between the two, which is 0.4 (i.e., $0.4=|4.3-3.9|$ ). Given that consumers generally prefer products with higher ratings than others, the reference point for a high-rated product would be the rating of the low-rated product ${ }^{9}$.

According to the Weber's law, the perceived difference would increase more slowly than the increase of the actual difference ${ }^{43}$. For example, when ratings 3.8 and 4.8 are compared, their perceived difference is less than five times the difference between ratings 4.6 and 4.8 (i.e., perceived $|4.8-3.8|$ $<5 \cdot$ perceived $|4.8-4.6|$ ). If we strictly apply the law in this case, the 
perceived difference between ratings 4.6 and 4.8 is expected to be equal to the difference between ratings 3.8 and 3.64 and not to 3.6 (i.e., perceived $4.8-4.6 \mid=$ perceived $|3.8-3.64|$ ). As Weber's law indicates, the perceived difference is proportional to the ratio that distinguishes the two numbers, and the perceived difference is interpreted as a marginally decreasing unit effect of a variable ${ }^{48}$.

The different rating perception mechanism of consumers during online shopping is often discussed in business literature ${ }^{61}$, indicating that the value of a product can be perceived differently depending on the purpose of behaviors (e.g., whether it is for searching or valuing). For example, Senecal et al. $^{28}$ found that consumers are often more critical and cautious about product quality when comparing two competing products, which may generate a mental scaling effect similar to that in Weber's law. According to Teo and Yeong ${ }^{19}$, alternative search is one of the most critical processes when making a purchase, which verifies consumers' intrinsic confidence in the quality of a product. From this argument, we develop the following hypothesis.

$\mathrm{H} 2$ : When online consumer ratings are referred to in comparing two products, the marginal impact of the difference in the rating of the two products on purchase intention decreases as rating difference increases.

Table 2. Hypotheses development

\begin{tabular}{|c|c|c|c|}
\hline $\begin{array}{l}\text { Assessment } \\
\text { types }\end{array}$ & $\begin{array}{l}\text { Perceived Magnitude of the } \\
\text { Observed Ratings }\end{array}$ & Examples & $\begin{array}{l}\text { Impact of Ratings on } \\
\text { Consumers }\end{array}$ \\
\hline Valuing & $\begin{array}{l}\text { The difference between the } \\
\text { rating of a product and the } \\
\text { rating of the product } \\
\text { reserved for the lowest } \\
\text { possible rating (i.e., null or } \\
\text { zero) }\end{array}$ & $\begin{array}{c}\text { When a consumer } \\
\text { perceives a rating of } 4.2 \text {, } \\
\text { this rating is the } \\
\text { difference between } 4.2 \\
\text { and } 0 \text { (null). }\end{array}$ & $\begin{array}{l}\text { H1: As rating increases, } \\
\text { its marginal effect on } \\
\text { purchase intention } \\
\text { decreases. }\end{array}$ \\
\hline Comparing & $\begin{array}{l}\text { The difference between the } \\
\text { ratings of two products } \\
\text { being compared }\end{array}$ & $\begin{array}{l}\text { When two products with } \\
\text { the ratings } 4.2 \text { and } 3.8 \\
\text { are compared, a } \\
\text { consumer perceives a } \\
\text { rating difference of } 0.4 \text {. }\end{array}$ & $\begin{array}{c}\mathrm{H} 2 \text { : As rating } \\
\text { difference increases, its } \\
\text { marginal effect on } \\
\text { purchase intention } \\
\text { difference decreases. }\end{array}$ \\
\hline
\end{tabular}




\section{RESEARCH METHOD}

\subsection{Experiment Design}

To measure the marginal effects of ratings, we designed an experiment as follows. First, we prepare a webpage with 13 similar TV sets displayed side by side to test the marginal effect of rating when used to value a product (H1). To control the effects of exogenous variables such as brand and price ${ }^{62}$, we copied the pictures and descriptions of the products from the bestselling TV list on Amazon.com and standardized them into the same formats. We also informed the respondents that these TV sets have almost identical specifications in terms of price, brand power, functions, and popularity that they consider purchasing. We then ask the respondents to reveal their purchase intention toward these products when they are shown various TV sets with different consumer ratings from the next page.

From the second page, we show 13 similar TV sets with different ratings (one TV set per page) and ask respondents for their purchase intentions. When the TV is displayed in an individual webpage, any information that can significantly affect consumer decision making other than the rating is carefully eliminated ${ }^{11}$. Only the rating, standardized picture, and short description are displayed in the page. The ratings of the 13 TV sets vary from 2.6 to 5.0 based on a five-point Likert scale, similar to the product pages on Amazon.com.

To test the marginal effect of the rating difference $(\mathrm{H} 2)$ when the respondents refer to the ratings to compare products, we show nine pairs of products with different ratings ranging from 3.8 to 5.0. The ranges of the ratings are relatively high, because the comparison of ratings usually occurs when the ratings are relatively high; thus, the products are considered for actual purchase. If the ratings are low, consumers would neither consider purchasing the product nor compare it with other products ${ }^{9}$. Thus, products with ratings higher than $75 \%$ (i.e., 3.75 out of 5) are used for this experiment.

We first selected six sets of similar TVs (12 products paired by twos), one of which has a 5.0 rating. We pair one product with a 5.0 rating with a product that has a rating lower than 5.0, because people usually compare products with the highest rating for possible alternatives. We also select three more sets of products with mid-level ratings, because these ratings frequently appear in online shopping malls ${ }^{63}$. We show a total of nine sets of product pairs in the following orders: 5.0-4.8; 5.0-4.6; 5.0-4.4; 5.0-4.2; 5.0$4.0 ; 5.0-3.8 ; 4.4-4.2 ; 4.4-4.0 ; 4.4-3.8$. We then asked for the purchase intention differences of the respondents for each set. 
TV sets are selected as a sample product for the following reasons. First, it is the product consumed by a large group of consumers without significant gender or age biases. Also, it is one of the products that are widely sold online ${ }^{10}$. Most online customers are familiar with the products and the situations they may face when buying them online. Lastly and most importantly, this product is one of the search goods with objective specifications and classes. Numerous studies have shown that the purchase decisions regarding TV sets are significantly affected by rating as an exemplary searched good ${ }^{17}$.

\subsection{Data Collection and Respondent Demographics}

Data collection was outsourced to Embrain Co. (www.embrain.com), a large market research company in Korea with more than 1.8 million panels in various Asian countries. For our survey, the company first sent e-mail invitations to the targeted panels; if the recipients accepted the offer to participate, they were guided to the Web sites we built. The invitation continued until 250 panels accepted the offer.

To ensure that respondents fully understood the survey context, we provided three screening questionnaires before the survey. The respondents were asked whether they had experience in online shopping, backpacking, and social media. If a respondent responded negatively to the first question (i.e., no experience in online shopping), they were not allowed to participate further in the survey. A total of 226 panels out of 250 answered that they have experience with online shopping. Thus, they participated in the survey. Answers on backpacking and social media did not affect the survey and were discarded.

To ensure data authenticity, Embrain was employed, as it has established a solid reputation for managing panels. The company carefully selects participants from a pool of panels based on the clients' specific requests. The company also keeps a track record of respondents to control the panel integrity. If inconsistency is detected during a panel's responses, the data from that panel is discarded, and the participant is excluded from the panel pool (i.e., company policy on spurious panels).

Lastly, to avoid any bias from demographic factors, data were controlled with almost equal distributions of gender and age. Furthermore, we conduct ANOVA tests at the construct level and confirmed that no significant difference existed in answering the questions across gender or age. The significance levels of ANOVA tests on the constructs across age and gender groups ranged from 0.16 to 0.94 , thus showing no significant difference across groups (Table 3 ). 
Table 3. Demographics of Respondents

\begin{tabular}{cccccc}
\hline Gender & Freq (\%) & Age & Freq $(\%)$ & $\begin{array}{c}\text { Internet Shopping } \\
\text { Experience }\end{array}$ & Freq (\%) \\
\hline Male & $105(46.5)$ & $19-29$ & $60(26.5)$ & None & $0(0)$ \\
Female & $121(53.5)$ & $30-39$ & $72(31.9)$ & Less than five times & $10(4.4)$ \\
Total & $\mathbf{2 2 6 ( 1 0 0 )}$ & $40-49$ & $50(22.1)$ & From time to time & $89(39.4)$ \\
& & $50-59$ & $44(19.5)$ & Often & $127(56.2)$ \\
& & Total & $\mathbf{2 2 6 ( 1 0 0 )}$ & Total & $\mathbf{2 2 6 ( 1 0 0 )}$ \\
\hline
\end{tabular}

\section{DATA ANALYSIS AND RESULT}

\subsection{When Consumers Refer to Rating for Product Valuing: $\mathrm{H} 1$ Test}

To test $\mathrm{H} 1$, we collect data from 13 datasets with ratings ranging from 2.6 to 5.0, with 0.2 differences in each class. Table 4 shows the mean and standard deviation of the 13 datasets. Table 5 shows the $t$-test results to indicate whether the rating difference shows a significant difference in purchase intention among the groups. The $t$-test result shows that 6 out of 12 cases demonstrate a significant difference in purchase intention as the ratings increase.

The original form of Weber's Law, which shows a decreasing marginal effect, is $y_{P I(A)}=\beta_{0}+\beta_{1} \cdot \ln x_{R(A)}+\varepsilon 59$. However, for simplicity and a parsimonious analysis, we take the simplest form of the logarithm function $^{59,64}$, as shown below (see Equation 1). The modified function still clearly indicates the main idea that the rating would show a marginally decreasing effect on consumer purchase intention, while the original diminishing marginal effect of the rating is not affected.

$$
y_{P I(A)}=\beta_{0}+\beta_{1} \cdot x_{R(A)}+\beta_{2} \cdot \sqrt{x_{R(A)}}+\varepsilon \quad \text { Equation (1) }
$$

where

$$
\begin{aligned}
& y_{P I(A)}=\text { Purchase Intention of product A } \\
& x_{R(A)}=\text { Consumer rating of product A } \\
& \varepsilon=\text { Randon error }
\end{aligned}
$$


Table 4. Data description

\begin{tabular}{ccc}
\hline $\begin{array}{c}\text { Product } \\
\text { Rating }\end{array}$ & \multicolumn{2}{c}{ Purchase Intention } \\
\hline 2.60 & 4.78 & S.D. \\
\hline 2.80 & 4.46 & 1.88 \\
3.00 & 5.35 & 1.67 \\
3.20 & 5.62 & 2.05 \\
3.40 & 5.35 & 1.82 \\
3.60 & 5.31 & 1.68 \\
3.80 & 5.68 & 1.90 \\
4.00 & 6.08 & 1.54 \\
4.20 & 6.32 & 1.53 \\
4.40 & 6.30 & 1.93 \\
4.60 & 6.26 & 1.83 \\
4.80 & 6.28 & 1.74 \\
5.00 & 6.75 & 2.13 \\
Total & 5.73 & 1.95 \\
\hline
\end{tabular}

Table 5. $t$-test result on 13 datasets

\begin{tabular}{cccc}
\hline $\begin{array}{c}\text { Compared } \\
\text { groups }\end{array}$ & $t$-value & Sig. Level & $\begin{array}{c}\text { Mean } \\
\text { difference }\end{array}$ \\
\hline $2.6-2.8$ & 1.748 & $\underline{0.081}$ & 0.327 \\
$2.8-3.0$ & 5.316 & $\underline{0.000}$ & 0.889 \\
$3.0-3.2$ & 1.584 & 0.114 & 0.279 \\
$3.2-3.4$ & 1.529 & 0.127 & 0.279 \\
$3.4-3.6$ & 0.188 & 0.851 & 0.031 \\
$3.6-3.8$ & 2.175 & $\underline{0.030}$ & 0.367 \\
$3.8-4.0$ & 2.480 & $\underline{0.014}$ & 0.402 \\
$4.0-4.2$ & 1.656 & $\underline{0.098}$ & 0.239 \\
$4.2-4.4$ & 0.135 & 0.893 & 0.022 \\
$4.4-4.6$ & 0.225 & 0.822 & 0.040 \\
$4.6-4.8$ & 0.105 & 0.916 & 0.018 \\
$4.8-5.0$ & 2.590 & $\underline{0.010}$ & 0.473 \\
\hline
\end{tabular}

We conduct a hierarchical regression analysis using this formula to highlight the marginal effect of the control variable, i.e., square root term of $X_{R(A)}$. Hierarchical regression analysis displays the marginal effect of a control variable more effectively by comparing the model with and without a specific variable ${ }^{65}$

We formulate models A and B. A is a simple regression model that shows the rating effect on purchase intention in a linear form $\left(y_{P I(A)}=\beta_{0}+\beta_{1} \cdot x_{R(A)}+\varepsilon\right)$, whereas $\mathrm{B}$ is a model that shows the rating effect on purchase intention in non-linear form $\left(y_{P I(A)}=\beta_{0}+\beta_{1} \cdot x_{R(A)}+\beta_{2} \cdot \sqrt{x_{R(A)}}+\varepsilon\right)$. Table 6 shows the ANOVA test results for models $\mathrm{A}$ and $\mathrm{B}$. They indicate that both models can predict the dependent variable (i.e., purchase intention) to a statistically significant degree with their independent variables. 
Table 6. Model specification and ANOVA test results for $\mathrm{H} 1$

\begin{tabular}{|c|c|c|c|c|c|c|c|c|c|}
\hline \multirow[b]{2}{*}{ Model } & \multicolumn{3}{|c|}{ Model Summary } & \multicolumn{6}{|c|}{ ANOVA } \\
\hline & $\begin{array}{c}\mathrm{R} \\
\text { Square }\end{array}$ & $\begin{array}{l}\text { Adjusted } \\
\text { R Square }\end{array}$ & $\begin{array}{l}\text { Std. } \\
\text { Error }\end{array}$ & & $\begin{array}{l}\text { Sum of } \\
\text { Squares }\end{array}$ & df & $\begin{array}{l}\text { Mean } \\
\text { Square }\end{array}$ & $\mathrm{F}$ & Sig. \\
\hline \multirow{3}{*}{ A } & \multirow{3}{*}{0.096} & \multirow{3}{*}{0.096} & \multirow{3}{*}{1.851} & Regression & 1069.646 & 1 & 1069.646 & 312.198 & .00 \\
\hline & & & & Residual & 10059.274 & 2936 & 3.426 & & \\
\hline & & & & Total & 11128.920 & 2937 & & & \\
\hline \multirow{3}{*}{ B } & \multirow{3}{*}{0.097} & \multirow{3}{*}{0.096} & \multirow{3}{*}{1.850} & Regression & 1078.870 & 2 & 539.435 & 157.536 & .00 \\
\hline & & & & Residual & 10050.050 & 2935 & 3.424 & & \\
\hline & & & & Total & 11128.920 & 2937 & & & \\
\hline
\end{tabular}

Table 7. Hierarchical Regression Analysis Summary for H1

\begin{tabular}{|c|c|c|c|c|c|c|}
\hline \multirow[t]{2}{*}{ Model } & \multirow[t]{2}{*}{ Terms } & \multicolumn{2}{|c|}{ Unstandardized Coefficients } & \multirow{2}{*}{$\begin{array}{c}\text { Standardized } \\
\text { Coefficients } \\
\text { Beta }\end{array}$} & \multirow[t]{2}{*}{$t$} & \multirow[t]{2}{*}{ Sig } \\
\hline & & Beta & Std. Error & & & \\
\hline \multirow{2}{*}{ A } & Constant & 2.671 & .177 & & 15.110 & .00 \\
\hline & $x_{R(A)}$ & .806 & .046 & .310 & 17.669 & .00 \\
\hline \multirow{3}{*}{ B } & Constant & -3.504 & 3.766 & & -.930 & .35 \\
\hline & $x_{R(A)}$ & -.865 & 1.019 & -.332 & -.848 & .40 \\
\hline & $\sqrt{x_{R(A)}}$ & 6.456 & 3.934 & .643 & 1.641 & .10 \\
\hline
\end{tabular}

Model A: $y_{P I(A)}=\beta_{0}+\beta_{1} \cdot x_{R(A)}+\varepsilon$

Model B: ${ }_{P I(A)}=\beta_{0}+\beta_{1} \cdot x_{R(A)}+\beta_{2} \cdot \sqrt{x_{R(A)}}+\varepsilon$

Table 7 shows the result of the hierarchical regression analysis test. When the non-linear effect is not assumed as in model $\mathrm{A},{ }^{x_{R(A)}}$ shows a significant linear effect on purchase intention ( $\mathrm{p}$-value $=0.000<0.01$ ). However, when marginal effect is assumed as in model B, the linear effect of $x_{R(A)}$ becomes insignificant ( $\mathrm{p}$-value $=0.396>0.1$ ), whereas the decreasing marginal effect of ${ }^{x_{R(A)}}$ is significant at 0.1 level $(\mathrm{p}$-value $=0.10)$. The comparison of models $\mathrm{A}$ and $\mathrm{B}$ indicates that ratings generally have a positive effect on purchase intention, and the form of its effect is more curvilinear than linear because the significance level of $\sqrt{x_{R(A)}}$ is lower than that of $x_{R(A)}$ in model B. 


\subsection{When Consumers Refer to Rating for Product Comparisons: $\mathrm{H} 2$ Test}

To test $\mathrm{H} 2$, we collect data from 9 rating comparison datasets with ratings ranging from 3.8 to 5.0. Table 4 shows the mean and standard deviation of the 9 datasets. These datasets were grouped into 6 subsets based on rating difference. For example, the data comparing 4.2 and 4.4 and that comparing 4.8 and 5.0 are grouped into one because they have the same rating difference of 0.2 . Table 9 shows the $t$-test results of the statistical difference among the six groups. As shown in Table 9, 3 out of 5 cases do not show a significantly different purchase intention difference across groups.

Table 8. Data description

Table 9. $t$-test result on 5 datasets

\begin{tabular}{|c|c|c|c|}
\hline \multirow[t]{2}{*}{$\begin{array}{l}\text { Compared } \\
\text { products }\end{array}$} & \multirow[t]{2}{*}{$\begin{array}{c}\text { Rating } \\
\text { Difference }\end{array}$} & \multicolumn{2}{|c|}{$\begin{array}{l}\text { Purchase } \\
\text { Intention } \\
\text { difference }\end{array}$} \\
\hline & & Mean & S.D. \\
\hline 4.4 vs. 3.8 & 0.6 & .99 & 1.72 \\
\hline 4.4 vs. 4.0 & 0.4 & .95 & 2.14 \\
\hline 4.4 vs. 4.2 & 0.2 & .59 & 1.91 \\
\hline 5.0 vs. 3.8 & 1.2 & 1.22 & 1.64 \\
\hline 5.0 vs. 4.0 & 1.0 & 1.31 & 1.87 \\
\hline 5.0 vs. 4.2 & 0.8 & 1.07 & 1.64 \\
\hline 5.0 vs. 4.4 & 0.6 & 1.24 & 1.32 \\
\hline 5.0 vs. 4.6 & 0.4 & .70 & 1.78 \\
\hline \multirow[t]{2}{*}{5.0 vs. 4.8} & 0.2 & .63 & 1.51 \\
\hline & Total & .97 & 1.76 \\
\hline
\end{tabular}

Compared Rating
difference $\quad t$-value Sig. Level $\begin{gathered}\text { Mean } \\ \text { difference }\end{gathered}$

To examine the marginal effect of rating difference, we formulate the model as follows (see Equation 2). The square root model for decreasing the marginal effect of rating difference on purchase intention is:

$y_{P I(A-B)}=\beta_{0}+\beta_{1} \cdot x_{R(A-B)}+\beta_{2} \cdot \sqrt{x_{R(A-B)}}+\varepsilon$ Equation (2)

where

$y_{P I(A-B)}=$ Purchase Intention difference between product $\mathrm{A}$ and $\mathrm{B}$ (when $A>B$ )

$x_{R(A-B)}=$ Rating difference between product $\mathrm{A}$ and $\mathrm{B}$ (when $A>B$ )

$\varepsilon=$ Error term 
Table 10. Model specification and ANOVA test results for $\mathrm{H} 2$

\begin{tabular}{|c|c|c|c|c|c|c|c|c|c|}
\hline \multirow[b]{2}{*}{ Model } & \multicolumn{3}{|c|}{ Model Summary } & \multicolumn{6}{|c|}{ ANOVA } \\
\hline & $\begin{array}{c}\mathrm{R} \\
\text { Square }\end{array}$ & $\begin{array}{l}\text { Adjusted } \\
\text { R Square }\end{array}$ & $\begin{array}{l}\text { Std. } \\
\text { Error }\end{array}$ & & $\begin{array}{l}\text { Sum of } \\
\text { Squares }\end{array}$ & $\mathrm{df}$ & $\begin{array}{l}\text { Mean } \\
\text { Square }\end{array}$ & $\mathrm{F}$ & Sig. \\
\hline $\mathrm{A}$ & .016 & .016 & 1.743 & $\begin{array}{c}\text { Regression } \\
\text { Residual } \\
\text { Total } \\
\end{array}$ & $\begin{array}{c}100.959 \\
6175.201 \\
6276.159 \\
\end{array}$ & $\begin{array}{c}1 \\
2032 \\
2033 \\
\end{array}$ & $\begin{array}{c}100.959 \\
3.039\end{array}$ & 33.221 & .00 \\
\hline B & .018 & .017 & 1.742 & $\begin{array}{c}\text { Regression } \\
\text { Residual } \\
\text { Total }\end{array}$ & $\begin{array}{c}113.504 \\
6162.655 \\
6276.159\end{array}$ & $\begin{array}{c}2 \\
2031 \\
2033\end{array}$ & $\begin{array}{c}56.752 \\
3.034\end{array}$ & 18.704 & .00 \\
\hline
\end{tabular}

Table 11. Hierarchical regression analysis summary for $\mathrm{H} 2$

\begin{tabular}{|c|c|c|c|c|c|c|}
\hline \multirow[t]{2}{*}{ Model } & \multirow[t]{2}{*}{ Terms } & \multicolumn{2}{|c|}{ Unstandardized Coefficients } & \multirow{2}{*}{$\begin{array}{c}\text { Standardized } \\
\text { Coefficients } \\
\text { Beta }\end{array}$} & \multirow[t]{2}{*}{$t$} & \multirow[t]{2}{*}{ Sig. } \\
\hline & & Beta & Std. Error & & & \\
\hline \multirow{2}{*}{ A } & Constant & .557 & .081 & & 6.887 & .00 \\
\hline & $x_{R(A-B)}$ & .682 & .118 & .127 & 5.764 &.$\underline{.00}$ \\
\hline \multirow{3}{*}{ B } & Constant & -.426 & .490 & & -.869 & $\overline{.39}$ \\
\hline & $x_{R(A-B)}$ & -1.130 & .899 & -.210 & -1.257 & .21 \\
\hline & $\sqrt{x_{R(A-B)}}$ & 2.781 & 1.368 & .340 & 2.033 & .04 \\
\hline
\end{tabular}

The ANOVA test results in Table 10 show that the independent variable in both models, $x_{R(A-B)}$, has a significant effect on the dependent variable, $y_{P(A-B)}$. Table 11 presents a hierarchical regression analysis result that highlights the marginal effect of rating difference. When the non-linear effect is not assumed as in model A, a significant linear effect of $x_{R(A-B)}$ is observed ( $p$-value $=0.00<0.01)$. However, when the non-linear effect is assumed as in model $\mathrm{B}$, it only shows a significant non-linear effect $(p$-value $=0.04<0.05)$ rather than a linear effect $(p$-value $=0.21>0.1)$. Thus, rating difference has a positive effect on purchase intention difference (e.g., the larger the gap between rating, the larger difference in purchase intention), but its unit effect on purchase intention difference decreases as the difference increases. Thus, $\mathrm{H} 2$ is supported. 


\section{DISCUSSION}

\subsection{Summary of Findings}

Based on the $\mathrm{H} 1$ and $\mathrm{H} 2$ tests, we summarize the findings below. First, when the rating information is used to estimate the value of a single specific product, the unit impact of rating decreases as the rating itself increases (H1).

Second, when the rating information is used to compare multiple products, the unit impact of the rating difference decreases as the difference itself increases (H2). In other words, when consumers compare multiple products with their ratings, they become more sensitive to the rating difference when it is more subtle, such as that between 4.2 and 4.3, than when the difference is obvious, such as that between 4.1 and 4.9 (summarized in Table 12).

Table 12. Summary of results

Tests Result Findings \& Interpretations of the Result

H1 Supported product, they become less sensitive to the rating changes as long as the ratings are above a certain critical level.

When consumers refer rating information to compare multiple products, they become more sensitive to rating

$\mathrm{H} 2$ Supported changes as the rating difference decreases, such as that between 4.3 and 4.4 , than when it is larger, such as that between 4.1 and 4.9 .

\subsection{Academic Contribution}

This study contributes to the literature in the following facets. First, using Weber's law, we explain the nonlinear effect of online consumer ratings. The majority of previous studies consider ratings as given numeric variables that are not perceived differently by different people ${ }^{9}$. However, the present study argues that even the same rating can be perceived differently because of the mental scaling effect caused by the specific situations consumers face. We attribute the different effects of rating on consumer purchase intention to their varied mentalities, which have different scaling systems. Thus, the perception of rating is not proportional to the change; rather, such a perception shows a heuristic response. This finding contributes to the literature by explaining why the ratings in 
previous studies have often shown different effects based on their circumstance.

Second, we identify the two most fundamental assessment activities of consumers regarding rating as valuing and comparing. Numerous studies on online consumers' assessment behaviors have been published ${ }^{66}$. However, the present study is distinguishable because of its parsimonious and exhaustive conceptualization of assessment behaviors. We not only propose these two types of assessment but also introduce them as a set of two activities that iterate until the completion of the shopping behaviour to explain why online shopping often goes through a long process of decision making without necessarily achieving a satisfactory outcome. Valuing and comparing have been frequently discussed in numerous studies ${ }^{67}$; however, we integrate them into a pair that accomplishes one shopping activity.

Lastly, we theorize and validate the marginally decreasing effect of a variable with significance and enhance the comprehension of Weber's law. Numerous studies have tested the nonlinear effects of variables ${ }^{68}$, but most of them show a marginally increasing effect (i.e., quadratic effect) with the use of the squared term of an independent variable ${ }^{69}$. We hence believe that the features of the marginally decreasing effect of significant factors in online business, such as online consumer ratings, must be also elucidated in view of the complexity of the real world and aim to contribute to the literature by showing that the effect of rating is gradually weakened, counter-intuitively, as its actual value increases.

\subsection{Practical Implication}

First, this study provides a basis for managing online consumer ratings from a seller's perspective by identifying an interesting pattern of the marginally decreasing effect of online consumer ratings. Managing consumer ratings is an important issue for sellers, because high online ratings are believed to necessarily generate high sales. Hence, certain sellers manage this problem by enhancing online communication channels with customers $^{70}$. However, if the marginally decreasing effect of higher rating can be acknowledged as in this study, practitioners may economize their resources not to excessively focus on online rating but to increase focus on other factors such as promotion and event ${ }^{62}$. Although a higher rating is generally preferred for improved performance ${ }^{71}$, the present study shows that its reward is not always guaranteed if the rating reaches a certain high level, such as a zone of tolerance. The present study suggests that the highest rating is not always the solution, and practitioners must consider the most efficient level of the consumer rating in such cases. 
Second, we introduce the concept of zone of tolerance to show practitioners that a critical point exists at which a consumer experiences a dramatic change in his or her purchase intention. This critical point provides practitioners with an approach for managing online consumer ratings. One obstacle in managing online consumer rating from the sellers' perspective is the fact that the rating is an exogenous factor that sellers cannot decide or control. However, using Weber's law, we show the possible existence of an absolute threshold of consumer purchase intention, regarding which sellers and practitioners should focus great attention.

Lastly, by presenting an application of Weber's law within the online shopping environment, this study demonstrates that ratings are often perceived subjectively rather than objectively, with the influence of circumstances and the context of online shopping. Consumers do not refer to ratings in just one instance; rather, these ratings often have multiple roles during shopping processes. This subjectivity in rating perception emphasizes that consumers' overall shopping situation should not be separated from its context. Considering that the online shopping environment is increasingly becoming more complicated, practitioners must recognize that the situation of a consumer must be accounted for in the rating effect.

\subsection{Limitation}

This study has limitations that can be addressed in future studies. First, sample size can be increased to strengthen the statistical rigor. The number of products with different ratings may not be sufficient to achieve statistical significance, as shown in the test results. In view of the vast amount of products with different ratings that were referred by consumers in real-world cases, we suggest that the real data must be analysed or the number of products must be increased. Second, future studies could expand the cases beyond valuing and comparing and could consider the pre- and postpurchase stages during which consumers refer to product ratings particularly. Third, the interaction effects of consumer rating on other important exogenous factors, such as price and brand, could be considered in future studies. Lastly, note that the sole effect of rating as investigated in this study may not effectively explain the overall effect of online word-of-mouth. Therefore, for future study, we propose that the effect of the consumer review should be examined together with the rating. The combined effects of consumer ratings and reviews will deepen the understanding on how consumer-generated product information is processed. 


\section{CONCLUSION}

This study presented how the same consumer ratings could be differently perceived by consumers depending on the purposes of the consumers who refer to ratings for product information. We conducted an experiment that contrasted rating differences between two products and measured how customer purchase intentions change as the degrees of differences change. As Weber's law previously indicated, the results of the study confirmed that the marginal effect of a rating could decrease as the rating increases and that the marginal effect of the rating differences could decrease as the rating difference increases. With these findings, this study achieved its academic goal of theoretically explaining why and how the scales and the contexts of consumer ratings differentiate the effects of various consumer ratings.

\section{ACKNOWLEDGEMENT}

This study is supported by Hankuk University of Foreign Studies (HUFS) Research Fund of 2018.

\section{REFERENCE}

[1] J. Choi, and L.V. Geistfeld, A cross-cultural investigation of consumer eshopping adoption. Journal of Economic Psychology, 25(6), p821-838, 2004. http://dx.doi.org/10.1016/j.joep.2003.08.006.

[2] C. Dellarocas, The digitization of word of mouth: Promise and challenges of online feedback mechanisms. Management Science, 49(10), p1407-1424, 2003. http://dx.doi.org/10.1287/mnsc.49.10.1407.17308.

[3] E. K. Clemons, G. G. Gao, and L. M. Hitt, When online reviews meet hyperdifferentiation: A study of the craft beer industry. Journal of Management Information Systems, 23(2), p149-171, 2006. http://dx.doi.org/10.1109/HICSS.2006.534.

[4] J. P. Singh, S. Irani, N. P. Rana, Y. K. Dwivedi, S. Saumya, and P. K. Roy, Predicting the "helpfulness" of online consumer reviews. Journal of Business Research, 70, p346-355, 2017. https://doi.org/10.1016/j.jbusres.2016.08.008.

[5] N. Hu, I. Bose, N. S. Koh, and L. Liu, Manipulation of online reviews: An analysis of ratings, readability, and sentiments. Decision Support Systems, $52(3)$ p674-684, 2012. http://dx.doi.org/10.1016/j.dss.2011.11.002.

[6] L.V. Casalo, C. Flavian, M. Guinaliu, and Y. Ekinci, Do online hotel rating schemes influence booking behaviors? International Journal of Hospitality

Management,

49 , p28-36.

2015. 
http://dx.doi.org/10.1016/j.ijhm.2015.05.005.

[7] B. L. Coker, Seeking the opinions of others online: Evidence of evaluation overshoot. Journal of Economic Psychology, 33(6), p10331042. 2012. http://dx.doi.org/10.1016/j.joep.2012.06.005

[8] M. Sun, How does the variance of product ratings matter? Management Science, 58(4), p696-707. 2012. http://dx.doi.org/10.1287/mnsc.1110.1458.

[9] J. Lee, and J. N. Lee, Understanding the product information inference process in electronic word-of-mouth: An objectivity-subjectivity dichotomy perspective. Information \& Management, 46(5), p302-311, 2009. http://dx.doi.org/10.1016/j.im.2009.05.004

[10] H. Baek, J. Ahn, and Y. Choi, Helpfulness of online consumer reviews: readers' objectives and review cues. International Journal of Electronic Commerce, 17(2), p99-126, 2012. http://dx.doi.org/10.2753/JEC10864415170204.

[11] T. Sasaki, D.V. Becker, M.A. Janssen, and R. Neel, Does greater product information actually inform consumer decisions? The relationship between product information quantity and diversity of consumer decisions. Journal of Economic Psychology, 32(3), p391398, 2011. http://dx.doi.org/10.1016/j.joep.2011.02.010.

[12] Y. Su, L. L. Rao, X. Li, Y. Wang, and S. Li, From quality to quantity: The role of common features in consumer preference. Journal of Economic Psychology, 33(6), p1043-1058, 2012. http://dx.doi.org/10.1016/j.joep.2012.07.002.

[13] A. Khare, L. I. Labrecque, and A. K. Asare, The assimilative and contrastive effects of word-of-mouth volume: An experimental examination of online consumer ratings. Journal of Retailing, 87(1), p111-126, 2011. http://dx.doi.org/10.1016/j.jretai.2011.01.005

[14] G. Cui, H. K. Lui, and X. Guo, The effect of online consumer reviews on new product sales. International Journal of Electronic Commerce, 17(1), p39-58, 2012.

[15] F. Zhu, and X. Zhang, Impact of online consumer reviews on sales: The moderating role of product and consumer characteristics. Journal of Marketing, $\quad$ 74(2), p133-148, 2010. http://dx.doi.org/10.1509/jmkg.74.2.133.

[16] R., Robinson, T. T. Goh, and R. Zhang, Textual factors in online product reviews: A foundation for a more influential approach to opinion mining. Electronic Commerce Research, 12(3), p301-330, 2012. http://dx.doi.org/10.1007/s10660-012-9095-7.

[17] J. Lee, J. N. Lee, and H. Shin, The long tail or the short tail: The category-specific impact of eWOM on sales distribution. Decision Support Systems, 51(3), p466-479, 2011. http://dx.doi.org/10.1016/j.dss.2011.02.011. 
[18] D.C. Edelman, Branding in the digital age. Harvard Business Review, 88(12), p62-69, 2010. http://dx.doi.org/10.1016/j.dss.2011.02.011.

[19] T. S. Teo, and Y. D. Yeong, Assessing the consumer decision process in the digital marketplace. Omega, 31(5), p349-363, 2003. http://dx.doi.org/10.1016/S0305-0483(03)00055-0.

[20] Dehaene, S., The neural basis of the Weber-Fechner law: A logarithmic mental number line. Trends in Cognitive Sciences, 7(4), p145-147, 2003. http://dx.doi.org/10.1016/S1364-6613(03)00055-X.

[21] A. Gupta, B. C. Su, and Z. Walter, An empirical study of consumer switching from traditional to electronic channels: A purchase-decision process perspective. International Journal of Electronic Commerce, 8(3), p131-161, 2004.

[22] R. Kohli, S. Devaraj, and M. A. Mahmood, Understanding determinants of online consumer satisfaction: A decision process perspective. Journal of Management Information Systems, 21(1), p115136, 2004. http://dx.doi.org/10.1080/07421222.2004.11045796.

[23] S. Kim, and M. S. Eastin, Hedonic tendencies and the online consumer: An investigation of the online shopping process. Journal of Internet Commerce, 10(1), p68-90, 2011. http://dx.doi.org/10.1080/15332861.2011.558458.

[24] R. T. Frambach, H. C. Roest, and T.V. Krishnan, The impact of consumer internet experience on channel preference and usage intentions across the different stages of the buying process. Journal of Interactive Marketing, 21(2), p26-41, 2007. http://dx.doi.org/10.1002/dir.20079.

[25] K. L. Xie, Z. Zhang, and Z. Zhang, The business value of online consumer reviews and management response to hotel performance. International Journal of Hospitality Management, 43, p1-12, 2014. http://dx.doi.org/10.1016/j.ijhm.2014.07.007.

[26] W.W. Moe, Buying, searching, or browsing: Differentiating between online shoppers using in-store navigational clickstream. Journal of Consumer Psychology, 13(1), p29-39, 2003. http://dx.doi.org/10.1207/153276603768344762.

[27] B. Detlor, S. Sproule, and C. Gupta, Pre-purchase online information seeking: Search versus browse. Journal of Electronic Commerce Research, 4(2), p72-84, 2003.

[28] S. Senecal, P. J. Kalczynski, and J. Nantel, Consumers' decisionmaking process and their online shopping behavior: A clickstream analysis. Journal of Business Research, 58(11), p1599-1608, 2005. http://dx.doi.org/10.1016/j.jbusres.2004.06.003.

[29] W. K. Darley, C. Blankson, and D. J. Luethge, Toward an integrated framework for online consumer behavior and decision making process: A review. Psychology \& Marketing, 27(2), p94-116, 2010. 
http://dx.doi.org/10.1002/mar.20322.

[30] M. Salehan, and D. J. Kim, Predicting the performance of online consumer reviews: A sentiment mining approach to big data analytics. Decision Support Systems, 81, p30-40, 2016. http://dx.doi.org/10.1016/j.dss.2015.10.006.

[31] W.W. Moe, and D. A. Schweidel, Online product opinions: Incidence, evaluation, and evolution. Marketing Science, 31(3), p372-386, 2012. http://dx.doi.org/10.1287/mksc.1110.0662.

[32] J. A. Chevalier, and D. Mayzlin, The effect of word of mouth on sales: Online book reviews. Journal of Marketing Research, 43(3), p345-354, 2006. http://dx.doi.org/10.1509/jmkr.43.3.345.

[33] M. Berenson, D. Levine, K. A. Szabat, and T. C. Krehbiel, Basic Business Statistics: Concepts and Applications. AU: Pearson Higher Education, 2012.

[34] K. Robson, M. Farshid, J. Bredican, and S. Humphrey, Making sense of online consumer reviews: A methodology. International Journal of Market Research, 55(4), p521-537, 2013. http://dx.doi.org/10.2501/IJMR-2013-046.

[35] W. Duan, B. Gu, and A. B. Whinston, The dynamics of online word-ofmouth and product sales-An empirical investigation of the movie industry. Journal of Retailing, 84(2), p233-242, 2008. http://dx.doi.org/10.1016/j.jretai.2008.04.005.

[36] J. Yang, and E. S. Mai, Experiential goods with network externalities effects: An empirical study of online rating system. Journal of Business Research, 63(9), p1050-1057, 2010. http://dx.doi.org/10.1016/j.jbusres.2009.04.029.

[37] A. Adams, C. A. Di Benedetto, and R. Chandran, Can you reduce your package size without damaging sales? Long Range Planning, 24(4), p86-96, 1991. http://dx.doi.org/10.1016/0024-6301(91)90009-D.

[38] J. Berger, A.T. Sorensen, and S. J. Rasmussen, Positive effects of negative publicity: When negative reviews increase sales. Marketing Science, 29(5), p815-827, 2010. http://dx.doi.org/10.1287/mksc.1090.0557.

[39] Q. Ye, R. Law, B. Gu, and W. Chen, The influence of user-generated content on traveler behavior: An empirical investigation on the effects of e-word-of-mouth to hotel online bookings. Computers in Human Behavior, 27(2), p634-639, 2011. http://dx.doi.org/10.1016/j.chb.2010.04.014.

[40] Q. Ye, R. Law, and B. Gu, The impact of online user reviews on hotel room sales. International Journal of Hospitality Management, 28(1), p180-182. 2009. http://dx.doi.org/10.1016/j.ijhm.2008.06.011.

[41] Y. Zhao, S. Yang, V. Narayan, and Y. Zhao, Modeling consumer learning from online product reviews. Marketing Science, 32(1), p153- 
169. 2013. http://dx.doi.org/10.1287/mksc.1120.0755.

[42] J. Whalen, C. Gallistel, and R. Gelman, Nonverbal counting in humans: The psychophysics of number representation. Psychological Science, 10(2), p130-137, 1999. http://dx.doi.org/10.1111/1467-9280.00120.

[43] D. Grewal, and H. Marmorstein, Market price variation, perceived price variation, and consumers' price search decisions for durable goods. Journal of Consumer Research, 21(3), p453-460, 1994. http://dx.doi.org/10.1086/209410.

[44] D. Kahneman and A. Deaton, High income improves evaluation of life but not emotional well-being. Proceedings of the National Academy of Sciences, 107(38), p16489-16493. 2010. http://dx.doi.org/10.1073/pnas.1011492107

[45] Britt, S.H., How Weber's law can be applied to marketing. Business Horizons, 18(1), p21-29, 1975. https://doi.org/10.1016/00076813(75)90004-X

[46] K. B. Monroe, Buyers' subjective perceptions of price. Journal of Marketing Research, 10(1), p70-80, 1973. http://dx.doi.org/10.2307/3149411.

[47] M. Anderson, and J. Magruder, Learning from the crowd: Regression discontinuity estimates of the effects of an online review database. The Economic Journal, 122(563), p957-989. 2012. http://dx.doi.org/10.1111/j.1468-0297.2012.02512.x.

[48] G. Ye, The locus effect on inertia equity. Journal of Product \& Brand Management, 14(3), p206-210, 2005. http://dx.doi.org/10.1108/10610420510601076.

[49] H. W. Sinn, and R. S. Hotel, weber's law and the biological evolution of risk preferences. CESIFO Working Paper No. 770, 2002. https://doi.org/10.1023/A:1026384519480

[50] B. M. Van Praag, and A. Kapteyn, How sensible is the Leyden individual welfare function of income? A reply. European Economic Review, 38(9), p1817-1825, $1994 . \quad$ https://doi.org/10.1016/00142921(94)90052-3.

[51] B. Xiao, and I. Benbasat, E-commerce product recommendation agents: Use, characteristics, and impact. MIS Quarterly, 31(1), p137-209, 2007. http://dx.doi.org/10.2307/25148784.

[52] K. Mason, and J. Bequette, Product experience and consumer product attribute inference accuracy. Journal of Consumer Marketing, 15(4), p343-357, 1998. http://dx.doi.org/10.1108/07363769810225984.

[53] X. Li, and L.M. Hitt, Self-selection and information role of online product reviews. Information Systems Research, 19(4), p456-474, 2008. http://dx.doi.org/10.1287/isre.1070.0154.

[54] F. Zhu, and X. M. Zhang, Impact of online consumer reviews on sales: The moderating role of product and consumer characteristics. Journal 
of $\quad$ Marketing, 74(2), p133-148, 2010. http://dx.doi.org/10.1509/jmkg.74.2.133.

[55] Y. C. Xu, and H. W. Kim, Order effect and vendor inspection in online comparison shopping. Journal of Retailing, 84(4), p477-486, 2008. http://dx.doi.org/10.1016/j.jretai.2008.09.007.

[56] Y. Wan, S. Menon, and A. Ramaprasad, A classification of product comparison agents. Communications of the ACM, 50(8), p65-71, 2007. http://dx.doi.org/10.1145/1278201.1278208.

[57] A. Fiegenbaum, S. Hart, and D. Schendel, Strategic reference point theory. Strategic Management Journal, 17(3), p219-235, 1996. http://dx.doi.org/10.1002/(SICI)10970266(199603)17:3\%3C219::AID-SMJ806\%3E3.0.CO;2-N.

[58] H. R. Arkes, D. Hirshleifer, D. Jiang, and S. Lim, Reference point adaptation: Tests in the domain of security trading. Organizational Behavior and Human Decision Processes, 105(1), p67-81, 2008. http://dx.doi.org/10.1016/j.obhdp.2007.04.005.

[59] Lengwiler, Y., The origins of expected utility theory. In W. Hafner, and H. Zimmermann (Ed.), Vinzenz Bronzin's Option Pricing Models (p535-545). Springer , 2009. https://doi.org/10.1007/978-3-540-857112_26.

[60] W. Duan, B. Gu, and A. B. Whinston, Do online reviews matter? An empirical investigation of panel data. Decision Support Systems, 45(4), p1007-1016, 2008. http://dx.doi.org/10.1016/j.dss.2008.04.001.

[61] X. Li, When a good impression goes bad: The effect of goal changes on repeated attitudes enquires. Psychology \& Marketing, 18(9), p929-949, 2007.

[62] M. Park, and S. J. Lennon, Brand name and promotion in online shopping contexts. Journal of Fashion Marketing and Management: An International Journal, 13(2), p149-160, 2009. http://dx.doi.org/10.1108/13612020910957680.

[63] N. Hu, L. Liu, and V. Sambamurthy, Fraud detection in online consumer reviews. Decision Support Systems, 50(3), p614-626, 2011. http://dx.doi.org/10.1016/j.dss.2010.08.012

[64] S. S. Stevens, To honor Fechner and repeal his law : A power function, not a $\log$ function, describes the operating characteristic of a sensory system. Science, 133(3446), p80-86, 1961.

[65] J. F. Hair, R. E. Anderson, B. J. Babin, and W.C. Black, Multivariate data analysis. NJ: Pearson Prentice Hall, 2006.

[66] S. Senecal, and J. Nantel, The influence of online product recommendations on consumers' online choices. Journal of Retailing, 80(2), p159-169, 2004. http://dx.doi.org/10.1016/j.jretai.2004.04.001.

[67] J. Cho, Likelihood to abort an online transaction: influences from cognitive evaluations, attitudes, and behavioral variables. Information 
and Management, 41(7), p827-838, 2004. http://dx.doi.org/10.1016/j.im.2003.08.013.

[68] V. Basu, E. Hartono, A. L. Lederer, and V. Sethi, The impact of organizational commitment, senior management involvement, and team involvement on strategic information systems planning. Information \& Management, 39(6), p513-524, 2002. http://dx.doi.org/10.1016/S03787206(01)00115-X.

[69] W. Oh, and A. Pinsonneault, On the assessment of the strategic value of information technologies: conceptual and analytical approaches. MIS Quarterly, 6(1), p239-265. 2007. http://dx.doi.org/10.2307/25148790.

[70] M. Sigala, E-service quality and Web 2.0: Expanding quality models to include customer participation and inter-customer support. The Service Industries Journal, 29(10), p1341-1358, 2009. http://dx.doi.org/10.1080/02642060903026239.

[71] Y. Chen, and J. Xie, Online consumer review: Word-of-mouth as a new element of marketing communication mix. Management Science, 54(3), p477-491, 2008. http://dx.doi.org/10.1287/mnsc.1070.0810. 